\title{
O REAL MARAVILHOSO EM GABRIEL GARCÍA MÁRQUEZ
}

\author{
Cinthia da Silva Belonia ${ }^{1}$
}

\begin{abstract}
RESUMO
Este artigo aborda o conceito do real maravilhoso na literatura hispano-americana, especialmente em Gabriel García Márquez. Pretende explicar a diferença entre o mágico, o maravilhoso e o fantástico, comumente confundida pelos leitores. Como corpus literário escolhemos o romance Del amor y otros demonios, no entanto as manifestações do real maravilhoso neste livro não são pontuadas no artigo devido ao curto espaço para um trabalho tão minucioso. O romance é utilizado apenas para exemplificar como García Márquez utiliza um fato real para construir uma narrativa no real maravilhoso. Para esta abordagem utilizamos os autores Irlemar Chiampi, Bella Jozef, Alejo Carpentier e outros.
\end{abstract}

Palavras-chave: Real maravilhoso. Realismo mágico. Realismo fantástico.

\begin{abstract}
This paper discusses the marvelous realism concept in Latin American Literature, focusing on Gabriel García Márquez. It attempts to explain the difference between magical, marvelous and fantastic, which are concepts often misinterpreted by readers. Garcia Márquez novel Del amor y otros demonios was used as a corpus, however the marvelous-real events of this book could not be developed in the discussion due to lack of space for such thorough work. The novel is used only to illustrate how García Márquez uses a fact to construct a narrative in marvelous realism. Other authors such as Irlemar Chiampi, Bella Jozef and Alejo Carpentier were used in order to do that approach.
\end{abstract}

Keywords: Marvelous Realism. Magical Realism. Fantastic Realism.

\section{INTRODUÇÃO}

Gabriel José García Márquez nasceu em 06 de março de 1927, na cidade de Aracataca, Colômbia, onde foi criado por seus avós, Dona Tranquilina Iguarán e o coronel Nicolás Ricardo Márquez Mejía. Com oito anos de idade, após a morte do avô, mudou-se para Barranquilla, onde passou a morar com os pais e os irmãos, tendo estudado no Liceu Nacional de Zipaquirá. Mudou-se para Bogotá em 1947 para dar continuidade à sua educação. Iniciou o curso de Direito na Universidade Nacional da Colômbia, mas não chegou a concluir a graduação.

\footnotetext{
${ }^{1}$ Universidade Federal Fluminense - UFF
} 
Antes de se tornar escritor, García Márquez foi jornalista, profissão iniciada em 1948 que jamais abandonou. A data é a de sua mudança para Cartagena das Índias (Colômbia), onde trabalhou no jornal El Universal. Em 1949 voltou para Barranquilla e passou a escrever no jornal El Heraldo. Em 1954 começou a trabalhar como repórter e crítico do jornal El Espectador. No ano de 1958 foi correspondente internacional na Europa e em 1961 mudou-se para New York trabalhando também como correspondente internacional. No entanto, devido à sua amizade com Fidel Castro e à crítica aos cubanos que abandonavam seu país para se exilarem nos Estados Unidos, García Márquez foi perseguido pela CIA, mudando-se para o México. Em 1982, foi agraciado com o Prêmio Nobel de Literatura pelo conjunto de sua obra.

A fama que acompanha o reconhecimento de seu trabalho não agrada ao autor, como se lê em El olor de La guayaba: conversaciones con Plinio Apuleyo Mendoza, obra publicada pela primeira vez em $1982^{2}$ :

(...) lo peor que le puede ocurrir a un hombre que no tiene vocación para el éxito literario, en un continente que no estaba preparado para tener escritores de éxito, es que sus libros se vendan como salchichas. Detesto convertirme en espectáculo público. Detesto la televisión, los congresos, las conferencias, las mesas redondas. (MÁRQUEZ, 1996, p. 36)

Sobre sua produção literária, Márquez diz que sempre escreveu a verdade, e que descobriu, ao fim de 30 anos, que, apesar de a verdade ser a melhor fórmula literária, muitas vezes os escritores se esquecem disso. Certamente ele usa esse argumento para se referir ao realismo maravilhoso presente em sua literatura, na qual muito do que escrevia eram fatos já mencionados por sua avó:

Me contaba las cosas más atroces sin conmoverse, como si fuera una cosa que acabara de ver. Descubrí que esa manera imperturbable y esa riqueza de imágenes era lo que más contribuía a la verosimilitud de sus historias. Usando el mismo método de mi abuela, escribí Cien años de soledad. (MÁRQUEZ, 1996, p. 43)

Quanto ao realismo mágico em sua literatura e nas demais produzidas na América hispânica, García Márquez diz, em conversa com Plinio Apuleyo Mendoza, que a realidade em um romance é diferente da realidade da vida, embora se apoie nela. Apuleyo diz acreditar que os leitores europeus de Márquez não conseguem ver a realidade que inspira o "mágico" em sua literatura. Márquez responde que, enquanto o

\footnotetext{
2 Todas as citações referentes à narrativa El olor de la guayaba: conversaciones con Plinio Apuleyo Mendoza são extraídas da edição de 1996.
}

RPI Revista de Pesquisa Interdisciplinar, Cajazeiras, v. 3, n. 2, p. 02-11, 2018. 
racionalismo dos europeus os impede de verem onde termina a realidade, os latinoamericanos veem que a realidade do cotidiano é repleta de fatos extraordinários, afirmando que não há em seus romances "una línea que no este basada en la realidad" (MÁRQUEZ, 1996, p. 52). Para Márquez, os latino-americanos esperam de um romance mais do que as opressões e injustiças que conhecem bem.Diz o autor que o tratamento "mítico" da realidade era encontrado nos relatos de sua avó:

Para ella, los mitos, las leyendas, las creencias de la gente, formaban parte, y de manera muy natural, de su vida cotidiana. Pensando en ella, me di cuenta de pronto que no estaba inventando nada, sino simplemente captando y refiriendo un mundo de presagios, de terapias, de premoniciones, de supersticiones, si tú quieres, que era muy nuestro, muy latino-americano. Recuerda, por ejemplo, aquellos hombres que en nuestro país consiguen sacarle de la oreja los gusanos a una vaca rezándole oraciones. Toda nuestra vida diaria, en América Latina, está llena de casos como éste. (MÁRQUEZ, 1996, p. 86)

Segundo Márquez, muitas vezes faltam palavras aos escritores para a representação dessa realidade desmedida. Ao escrever sobre um rio enorme, um europeu só consegue imaginar o Danúbio, que possui 2.790 quilômetros de comprimento, uma vez que não poderia imaginar, por exemplo, o Amazonas, onde não é possível, em certos pontos, de uma margem se enxergar a outra. Dizendo a Márquez que todo escritor escreve um grande livro, Apuleyo pergunta a ele qual seria o seu.Márquez responde que é o livro da solidão. De fato, tal tema não está presente apenas em Cien años de soledad, mas em toda a sua obra.

\section{REALISMO MÁGICO}

O romance Del amor y otros demonios, escrito em 1994, tem como referência real uma reportagem jornalística de autoria de Gabriel García Márquez. A trama narrativa do romance se tece em torno da lembrança de uma lenda contada pela avó de García Márquez sobre uma marquesinha de 12 anos venerada pelos povos do Caribe devido aos inúmeros milagres a ela creditados. Dona de uma enorme cabeleira que se arrastava pelo chão como véu de noiva, a menina teria morrido em virtude da transmissão do vírus rábico (Rhabdoviridae) decorrente do ataque de um cão. No prólogo do romance, registra-se que, em 26 de outubro de 1949, o autor, ainda jornalista, foi assistir à demolição das criptas do Convento de Santa Clara em busca de notícias. A destruição do convento para a construção de um hotel de luxo, não foi, 
entretanto, o que chamou a atenção do jornalista, mas a ossatura encontrada em uma das criptas identificada como a de uma menina de aproximadamente doze anos, com uma enorme cabeleira cor de cobre pendente do crânio, medindo 22 metros e 11 centímetros: "La idea de que esa tumba pudiera ser la suya fue mi noticia de aquel día, y el origen de este libro" (MÁRQUEZ, 2007, p. 13). Em sua lápide havia apenas um nome sem sobrenomes: Sierva María de Todos los Ángeles. Antes que o tamanho do cabelo fosse contestado no local, o agente de obras explicou que os cabelos humanos crescem um centímetro por mês mesmo após a morte, e que vinte e dois metros eram compatíveis com os 200 anos da ossatura encontrada. Ali estava a notícia:

En la tercera hornacina del altar mayor, del lado del Evangelio, allí estaba la noticia. La lápida saltó en pedazos al primer golpe de la piocha, y una cabellera viva de un color de cobre intenso se derramó fuera de la cripta. El maestro de obra quiso sacarla completa con la ayuda de sus obreros, y cuanto más tiraban de ella más larga y abundante parecía, hasta que salieron las últimas hebras todavía prendidas a un cráneo de niña. En la hornacina no quedó nada más que unos huesecillos menudos y dispersos, y en la lápida de cantería carcomida por el salitre sólo era legible un nombre sin apellidos: Sierva María de Todos los Ángeles. (MÁRQUEZ, 2007, p. 123)

A construção da narrativa tem, pois, como referencial uma série de alegorias representativas do realismo maravilhoso na literatura latino-americanaque caracteriza o texto do autor. Em O realismo maravilhoso (1980), Irlemar Chiampi critica o uso indiscriminado do termo "realismo mágico", que surgiu nos anos de 1940 mantendo-se até 1950:

Realismo mágico veio a ser um achado crítico-interpretativo, que cobria, de um golpe, a complexidade temática (que era realista de um outro modo) do novo romance e a necessidade de explicar a passagem da estética realista-naturalista para a visão ("mágica") da realidade. (CHIAMPI, 1980, p. 19)

Esse novo realismo experimentava soluções técnicas para construir uma linguagem plurivalente do real. As formas renovadoras desses primeiros romances continham o embrião de onde surgiram as formas revolucionárias que atestavam o lúdico e o paródico nos anos sessenta e setenta. $\mathrm{O}$ conceito de realismo mágico expressava uma preocupação em constatar uma "nova atitude" do narrador diante do real: "E esse modo estranho, complexo, muitas vezes esotérico e lúcido, foi identificado genericamente como a 'magia"'.

RPI Revista de Pesquisa Interdisciplinar, Cajazeiras, v. 3, n. 2, p. 02-11, 2018. 
O termo realismo mágico foi cunhado em 1925 por Franz Roh. Em seu livro Nach Expressionismus (Magischer Realismus), Roh caracterizava a produção pictórica do pós-expressionismo alemão, cuja proposta era, segundo Chiampi, "representar as coisas concretas e palpáveis, para tornar visível o mistério que ocultam" (CHIAMPI, 1980, p. 21), como realista mágica. O primeiro a incorporar o termo à crítica do romance hispano-americano foi Arturo Uslar Pietri, em Letras y hombres de Venezuela, em 1948.

O texto do prólogo do romance do cubano Alejo Carpentier, El reino de este mundo, publicado em 1949, funcionou como uma espécie de manifesto da nova orientação ficcional. Nele, Carpentier, propondo a teoria do real maravilhoso, “estabelecia uma verdadeira profissão de fé como escritor e exortava os narradores latino-americanos a se voltarem para o mundo americano, cujo potencial de prodígios, garantia o autor, sobrepujava em muito a fantasia e a imaginação européia" (CHIAMPI, 1980, p. 32). Carpentier criticava os surrealistas por inventarem o mágico, enquanto que, na América Latina, os escritores escreviam sobre o que há de mágico no continente. Escreve ainda Chiampi que:

(...) é preciso reconhecer também, que, se a ideia de uma realidade maravilhosa não é uma criação teórica de Carpentier, a sua contribuição ao estágio pós-surrealista consiste em ter identificado concretamente uma entidade cultural, cujos traços da formação étnica e histórica são, a tal ponto, estranhos aos padrões racionais, que sejustifica a predicação metafórica do maravilhoso e do real. (CHIAMPI, 1980, p. $35)$

Além disso, as restrições que Carpentier faz ao surrealismo dirigem-se mais às fórmulas fantasistas e oníricas que ao ideário. Carpentier invoca a América primitiva, ainda não contaminada pela reflexividade, sendo capaz de concretizar o projeto de poetizar o real maravilhoso.

Segundo Chiampi, o melhor exemplo do real maravilhoso americano é "a sobrevivência de hinos mágicos que evocam os poderes licantrópicos do escravo Mackandal” (CHIAMPI, 1980, p. 37), cuja rebelião marcou as origens de um movimento independentista, levando os negros ao poder, nos fins do século XVIII. Chiampi explica a diferença entre mágico e maravilhoso:

Maravilhoso é termo já consagrado pela Poética e pelos estudos crítico-literários em geral, e se presta à relação estrutural com outros tipos de discursos (o fantástico, o realista). Mágico, ao contrário, é termo tomado de outra série cultural e acoplá-lo a realismo implicaria ora uma teorização de ordem fenomenológica (a "atitude do

RPI Revista de Pesquisa Interdisciplinar, Cajazeiras, v. 3, n. 2, p. 02-11, 2018. 
narrador"), ora de ordem conteudística (a magia como tema). (CHIAMPI, 1980, p. 43)

Segundo a autora, assim se define o maravilhoso:

\begin{abstract}
Maravilhoso é o "extraordinário", o "insólito", o que escapa ao curso ordinário das coisas e do humano. Maravilhoso é o que contém a maravilha, do latim mirabilia, ou seja, "coisas admiráveis" (belas ou execráveis, boas ou horríveis), contrapostas às naturalia. Em mirabilia está presente o "mirar": olhar com intensidade, ver com atenção, ou ainda, ver através. O verbo mirare se encontra também na etimologia de milagre - portento contra a ordem natural - e de miragem - efeito óptico, engano dos sentidos. O maravilhoso recobre, nesta acepção, uma diferença não qualitativa, mas quantitativa com o humano; é um grau exagerado ou inabitual do humano, uma dimensão de beleza, de força ou riqueza, em suma, de perfeição, que pode ser mirada pelos homens. Assim, o maravilhoso preserva algo do humano, em sua essência. A extraordinariedade se constitui da frequência ou densidade com que os fatos ou os objetos exorbitam as leis físicas e as normas humanas. (CHIAMPI, 1980, p. 48)
\end{abstract}

O realismo maravilhoso não é calculado para obter o estranhamento do leitor. A "maravilha" está presente na realidade, o insólito deixa de ser o "outro lado" para incorporar-se ao real. Os objetos, seres ou eventos são destituídos de mistério. Eles possuem perspectiva interna e não apelam para a necessidade de um deciframento por parte do leitor. O realismo maravilhoso se qualifica entre o efeito de encantamento e o relato.

Para Chiampi a casualidade no fantástico é questionada e no maravilhoso é ausente, ou seja, tudo pode acontecer sem se precisar justificar ou remeter aos realia:

O regime causal do realismo maravilhoso é ditado pela descontinuidade entre causa e efeito (no espaço, no tempo, na ordem de grandeza). Como já observou Borges, há uma necessária conexão, um vínculo inevitável entre coisas distantes numa narrativa em que a causalidade é "mágica". (CHIAMPI, 1980, p. 60)

Os personagens do realismo maravilhoso não se desconcertam com o sobrenatural. $\mathrm{O}$ tético e o não-tético (o real e o sobrenatural) combinam-se harmoniosamente. García Márquez, segundo Chiampi, exagera o efeito discursivo do encantamento no leitor ao explorar, à saciedade, a antinomia dos planos real e maravilhoso. Chiampi defende o "barroco" como o modo legítimo de narrar o latino-americano no romance real maravilhoso americano, além de relacioná-lo à nomeação dos objetos americanos não inscritos na cultura universal:

A informação do maravilhoso americano, associado à perspectiva crítica de uma linguagem inventiva e radical, contém profundas vinculações com a conjuntura

RPI Revista de Pesquisa Interdisciplinar, Cajazeiras, v. 3, n. 2, p. 02-11, 2018. 
ideológica e social. Alguns estudiosos da estética barroca, como Affonso Ávila, a interpretam como uma "rebelião através do jogo", que caracteriza, nos momentos traumáticos da História, a busca desalienante do artista, através do espetáculo lúdico das formas. Para além da erotização da escritura que o gozo verbal supõe, um profundo sentido revolucionário lateja no luxo descritivista, nas contorções e arabescos de imagens preciosas, na exuberância léxica ou no ritmo tenso e enérgico da frase barroca. (CHIAMPI, 1980, p. 87)

O termo real maravilhoso, ainda segundo Chiampi, é o que mais define a literatura hispano-americana, devido às lendas americanas (as Amazonas, os Canibais de um só olho, a Fonte da Eterna Juventude, o El Dorado, os Índios Gigantes, dentre outras)que atraíam grandes contingentes de povoadores seduzidos pelo maravilhoso. $\mathrm{O}$ termo "maravilha" era utilizado pelos cronistas para descrever os seres e objetos do Mundo Novo. Essas lendas, tanto as de milagres quanto as de monstros, identificaram a América como um "Reino das Maravilhas", pois muitos europeus acreditavam que o continente americano era um paraíso terrenal, onde se pudessem colher frutos sem muito trabalho, em uma terra sempre primaveril.

$\mathrm{O}$ verdadeiro critério para se postular uma diferença latino-americana com relação aos modelos europeus e norte-americanos, segundo Chiampi, é a mestiçagem. Arturo Uslar Pietri diz que a literatura hispano-americana nasce mesclada e impura, alcançando assim suas mais altas expressões. Sobre o fato de o real maravilhoso ser o termo que melhor se adequa a essa modalidade narrativa, Chiampi escreve:

Não que as reflexões de Carpentier sejam privilegiadas em justeza ou correção, mas pela expressividade do oximóron que instala em seu significante o significado da não disjunção e pela correlação terminológica permitida para falar-se de um tipo de narrativa dialógica, que nos anos cinquenta nasce na América Hispânica. Justamente quando se fixa no discurso americano o ideologema da mestiçagem. (CHIAMPI, 1980, p. 133-4)

O maravilhoso é naturalizado. O tom assertivo da narração é uma marca notória da intencionalidade de tornar legíveis a mirabilia como naturalia.

Segundo Bella Jozef, em A máscara e o enigma, a "nueva novela hispanoamericana" surge como forma de afastamento da tradição narrativa da América Hispânica. Sobre a realidade e a verossimilhança, ela escreve que a literatura "é sempre uma transposição da realidade e o realismo nunca poderá ser uma enunciação direta do real” (JOZEF, 2006, p. 188). Portanto, a literatura nunca é propriamente realista. Além disso, a nossa realidade é uma resposta "da realidade real dos americanos à realidade 
utópica da América" (JOZEF, 2006, p. 190). A realidade utópica da América Latina Hispânica é, pois, uma resposta à "realidade real" da América anglo-saxônica.

Além de Alejo Carpentier, outros escritores tentaram nomear a produção literária da América Hispânica. Bella Jozef cita alguns:

\begin{abstract}
Alejo Carpentier, no prólogo do romance El reino de este mundo refere-se ao "real maravilhoso" da América. Outros autores referiram-se ao "realismo mágico". Para Luís Leal, no "realismo mágico", o autor quer desentranhar o maravilhoso das coisas, captar os mistérios da realidade. Também ValbuenaBriones fala da coexistência de mito e fantasia no "realismo mágico". Para Angel Flores, o "realismo mágico" é uma mistura de real e fantástico. Suas ideias são dotadas por E. Dale Cartes, de cujas conclusões nos interessa uma, a de que o "realismo mágico" é a transformação do real em irreal. (JOZEF, 2006, p. 196)
\end{abstract}

Segundo Carpentier, a literatura hispano-americana representa-se no real maravilhoso que constitui o ethos cultural da América Latina. Dessa forma ele recusa o maravilhoso onírico dos surrealistas. Foi o vodu do Haiti, onde elementos mágicos se integram ao cotidiano dos haitianos, que constituiu sua fonte inicial de pesquisa para conceituar o realismo maravilhoso na América Latina.

\title{
CONCLUSÃO
}

O realismo mágico seria uma "maravilha" criada pelo artista a partir de uma realidade concreta. $\mathrm{O}$ mesmo também pode criar a magia e o fantástico. Já o "real maravilhoso", conceituado por Carpentier, não é criado, mas (re)presentado na literatura, uma vez que se constitui no ethos cultural hispano-americano. Ante as imprecisões conceituais causadas pelo uso indiscriminado do termo realismo mágico, William Splinder (1993), escritor e jornalista guatemalteco, define três modalidades: o realismo mágico metafísico, o realismo mágico antropológico e o realismo mágico ontológico. À luz de Antonio Esteves e Eurídice Figueiredo, em "Realismo Mágico e Realismo Maravilhoso", capítulo publicado no livro Conceitos de literatura e cultura, dentre as três modalidades apontadas, poderíamos dizer que o realismo mágico antropológico é a que melhor caracteriza a literatura produzidapor Gabriel García Márquez:

Nesse tipo de realismo mágico, o narrador normalmente tem duas vozes. Em alguns momentos usa o ponto de vista racional e em outras prefere o enfoque da magia, no 
qual aparecem referentes míticos e histórico-culturais de um determinado grupo étnico ou social (...). A palavra mágico, nesse caso, é tomada no sentido antropológico. Essa é a definição mais atual e específica de realismo mágico, estando fortemente associada à literatura latino-americana,e aproximando-se bastante do realismo maravilhoso de Carpentier. (ESTEVES, FIGUEIREDO, 2012, p. 412)

Os autores citados diferenciam o realismo mágico do realismo maravilhoso explicando que o primeiro é criado a partir de uma realidade concreta que o artista deforma com fins estéticos. Já no realismo maravilhoso o escritor narra uma realidade já existente, "referindo-se a um modo de ser de uma determinada realidade" (ESTEVES, FIGUEIREDO, 2012, p. 405). Segundo eles, no período entre as duas Grandes Guerrassurgiram, na América Latina, escritores que romperam com os modelos narrativos do século XIX, desconstruindo os cânones europeus. Esses escritores tentavam criar uma literatura que:

Focalizasse a crise do homem americano numa sociedade complexa que, ao mesmo tempo em que desejava ingressar na era industrial e tecnológica e seu universo urbano, ainda vivia em um mundo rural e agrário, salpicado por relações econômicas e sociais medievais, num período em que a Europa discutia formas de superação do capitalismo. (ESTEVES, FIGUEIREDO, 2012, p. 394)

Os escritores desse grupo eram heterogêneos na origem e no modo de escrever. No entanto, fizeram parte do movimento conhecido por boom da literatura latinoamericana. Devido à avalanche de textos, viu-se a necessidade de explicar o fenômeno. Foi assim que os termos realismo mágico e realismo maravilhoso começaram a ser usados indiscriminadamente, mais rotulando que conceituando a nova modalidade narrativa. Ora os termos se alternavam ora se opunham, podendo também se complementar. Esse problema ocorreu por décadas, uma vez que as poucas pesquisas mais profundas sobre a questão fizeram com que o uso do conceito proliferasse de forma confusa devido à falta de uma definição que não fosse controversa.

\section{BIBLIOGRAFIA}

CARPENTIER, Alejo. Prólogo. In: El reino de este mundo. São Paulo: Civilização Brasileira, 2003. 
CHIAMPI, Irlemar. O Realismo Maravilhoso. Forma e Ideologia no Romance Hispanoamericano. São Paulo: Perspectiva, 1980.

ESTEVES, Antonio, FIGUEIREDO, Eurídice. Realismo Mágico e Realismo Maravilhoso. In: FIGUEIREDO, Eurídice. (Org.). Conceitos de literatura e cultura. Niterói RJ/Juiz de Fora MG: EDUFF/UFJF, 2012.

FIGUEIREDO, Eurídice. (Org). Conceitos de literatura e cultura. Niterói RJ/Juiz de Fora MG: EDUFF/UFJF, 2012.

GARCÍA MÁRQUEZ, Gabriel; APULEYO MENDOZA, Plinio. El olor de la guayaba: conversaciones con Plinio Apuleyo Mendoza. Buenos Aires: Sudamericana, 1982.

Cien años de soledad. 3 ed. Buenos Aires: Sudamericana, 2009.

JOZEF, Bella. A máscara e o enigma. Rio de Janeiro: Francisco Aves, 2006. 